\title{
Autism Spectrum Disorders, Nutrition, Neurobiology and Special Education Services by 2020
}

\author{
Regina Enwefa* and Stephen Enwefa \\ Southern University, USA
}

Submission: November 10, 2017; Published: November 20, 2017

*Corresponding author: Regina Enwefa, Southern University A \& M College, Millwood Drive, \#86585,Baton Rouge, LA 70879, Louisiana, USA, Tel: 601-918-1713; Email: renwefa@gmail.com

\section{Editorial}

Autism spectrum disorders (ASD) have been defined as an array of conditions that are depicted by challenges with social skills, repetitive behaviors, speech and nonverbal communication according to the (National Institute of Mental Health 2016). From 1911 to present there has been a century of review of ASD in terms of the actual concept itself and the diagnostic criteria. ASD is within the group of disorders specifically named as developmental disorders [1]. ASD includes such a wide scope of symptoms, skills, and levels of disability. Individuals with ASD have many types of characteristics such as:

a. Continuing social problems that include challenges with communicating and interacting with others.

b. Some repetitive behaviors as well as a constraint to interest in activities surrounding their lives.

c. Can be recognized within the first two years of life.

d. The disorder impacts an individual's ability to function.

e. There is always a language deficit component association with ASD.

According to the [2] ASD is defined and classified as a complex developmental disorder that causes problems with thinking, feeling, language and the ability to relate to others. It is considered a neurological disorder that shows symptoms to be different in each person [3]. Over the years there have been a number of controversial factors surrounding the cause of ASD to be genetic and/or environmental. Today, ASD is viewed as a genetic and environmental result that impacts brain development.

\section{Demographics of Autism Spectrum Disorders}

Globally, ASD is estimated to affect 24.8 million people as of the year 2015. In the year 2010, the number of people affected was estimated at about 1-2 per 1000 worldwide. ASD occurs four to five times more often in boys than in girls [4,5]. There was about thirty percent increase in the number of children diagnosed with ASD in 2012. Christensen et al. [6,7] estimates that the prevalence for boys vs girls to be 1 in 42 boys and 1 in 189 girls respectively. One third of individuals with ASD will remain nonverbal, have an intellectual disability, and will battle the medical and mental health issues that are accompanied by ASD. Many children experience a combination of gastrointestinal disorders, sleep disturbances, seizures, food intolerances, picky eating, attention deficit and hyperactivity disorder (ADHD), anxiety and phobias. A symptom that is common in all ASD cases is language deficits although in some of the cases this may be subtle.

\section{Nutrition}

The importance of eating the right food is significant for our livelihood. Brain development requires the right nutrients to simply help those cell dendrites connect. Good nutrition helps children with ASD to function better and increases their tolerance to feel better. Many children with ASD are picky eaters, some will only eat a specific small amount of food supply, and there are some who eat just about anything that is placed in front of them [5]. Over the years there have been recommendations to provide children with ASD various omega 3 fatty acids (i.e., cod liver oil, walnuts), vitamin D, choline (recommend distribution under supervision), magnesium and calcium, vitamin B complex, and probiotics. Some children may be sensitive to be given herbal supplements by the way of pills, however, there are many companies who make chewable vitamins and some even have vitamins by using concentrated oral sprays. It is important for parents to understand how supplementation works and use the herbal treatment along with supervision from a pediatrician that have the knowledge, expertise, and experience working with ASD children. Another component of the nutritional plan is to 
review any and all sensitivities that the child may have towards oral and sensory processing difficulties. There are several issues that will need to be considered commonly associated with ASD. At least $36 \%$ of ASD children have challenges with smell, touch, sound, light, and visual aspects of food presentation [5]. Also, $45 \%$ of these children have issues with taste, $69 \%$ have issues with texture, and $22 \%$ have issues with temperature.

Taste, texture, and temperature is an important part of the eating process. Social skills and typical basic communication skills are challenging for ASD children. Many ASD children have difficulty with transition from on activity to another and simple novel situations that comes along with everyday school and home life. ASD program management specifically related to the Individualized Education Program (IEP) and/or Individualized Family Service Plans (IFSP) must include plans for nutrition at school and home [6-8]. It is highly recommended that professionals such as speech language pathologists, special education teachers, occupational therapists, and physical therapists teach parents, regular education teachers, and paraprofessionals by demonstration and practice for motivation and safety in eating. Enwefa \& Enwefa [5] designed a food journal to be used with ASD that related more to their cultural and diverse needs. Everything we do and eat surrounds culture, it impacts what and how we eat [9]. There are four key points to consider in planning a food journaling feeding program at home and school for ASD children as listed in Table 1.

Table 1: Suggestions for food journaling for ASD children.

\section{Table 1: Suggestions for Food Journaling for ASD Children}

- Consider what the child likes to eat.

- Write down all the food the child eats AM, PMI and/or special occasions.

- Consider portion size (i.e., size of the child's hand).

- Always begin the planning process observing and not judging the child.

- Take into consideration the texture/food type (i.e., soft, crunchy, hard) levels.

- Consider the senses (i.e., smell, taste, touch, and sound) of the food.

- Appearance is everything. Using different colors with consistency can be very effective.

- More importantly, to consider the child's mood. Also, parents and professionals can use daylight lighting, music and aromatherapy oils at the dining table and in classrooms at school.

- Plan for food exploration with utensils, the child's fingers, and visual guided steps as how to eat and swallow the food as part of the child's IEP/IFSP.

- Always plan for visuals, texture, smell, taste, sound, application in writing goab for feeding and they should be based on academic standards. Most professionals are able to design a food journaling program for children with ASD by also including the ap propriate feeding tools for child ren. Some suggestions to consider are to have plates, cups, forls, spocens, straws, placemat, tablecloth, food, shapes/sizes, napkins, and containers.

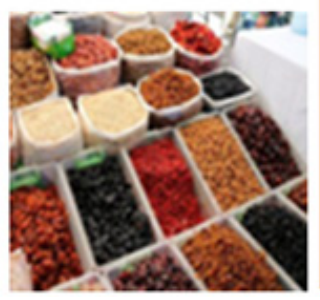

\section{One cannot think well, love well,} sleep well, if he has not dined well.

Virginia Wolf 
It is a necessity for parents and professionals to rely on various methods and procedures for improving the medical and the nutritional aspects of their child's mealtimes in order to continue to enhance proper brain and social development. ASD can be devastating to parents and also to the professionals who teach and design programs to accommodate them on a daily basis. It is imperative for professionals to design intervention programs that aid in increasing skills and improve functioning.

\section{Neurobiology of ASD}

Several theories have been suggested in the literature as to the cause of ASD; however, the specific cause remains unknown. ASD have been labeled a complex syndrome with several characteristics that are present in early childhood. The cause of ASD is still a mystery to the scientific community and has not been linked to the biogenetic, pathologic, radiologic, anatomic, and electroencephalographic evidences that many neurologists use for a clinical diagnosis of ASD. The reported features associated with ASD include executive dysfunction, self injurious behaviors, obsessive-compulsive disorder (OCD), intellectual deficits, seizures, depressions, motor deficits, attention issues-attention-deficit-hyperactive disorder (ADHD), sensory processing disorders, aggression, and tantrums. There are several areas to take into consideration for the neurological basis for ASD. See Table 2 below for Brain Areas Associated with ASD.

Table 2: Brain areas with typical deficits associated with ASD.

\section{Table 2: Brain Areas With Typical Deficits Associated with ASD}

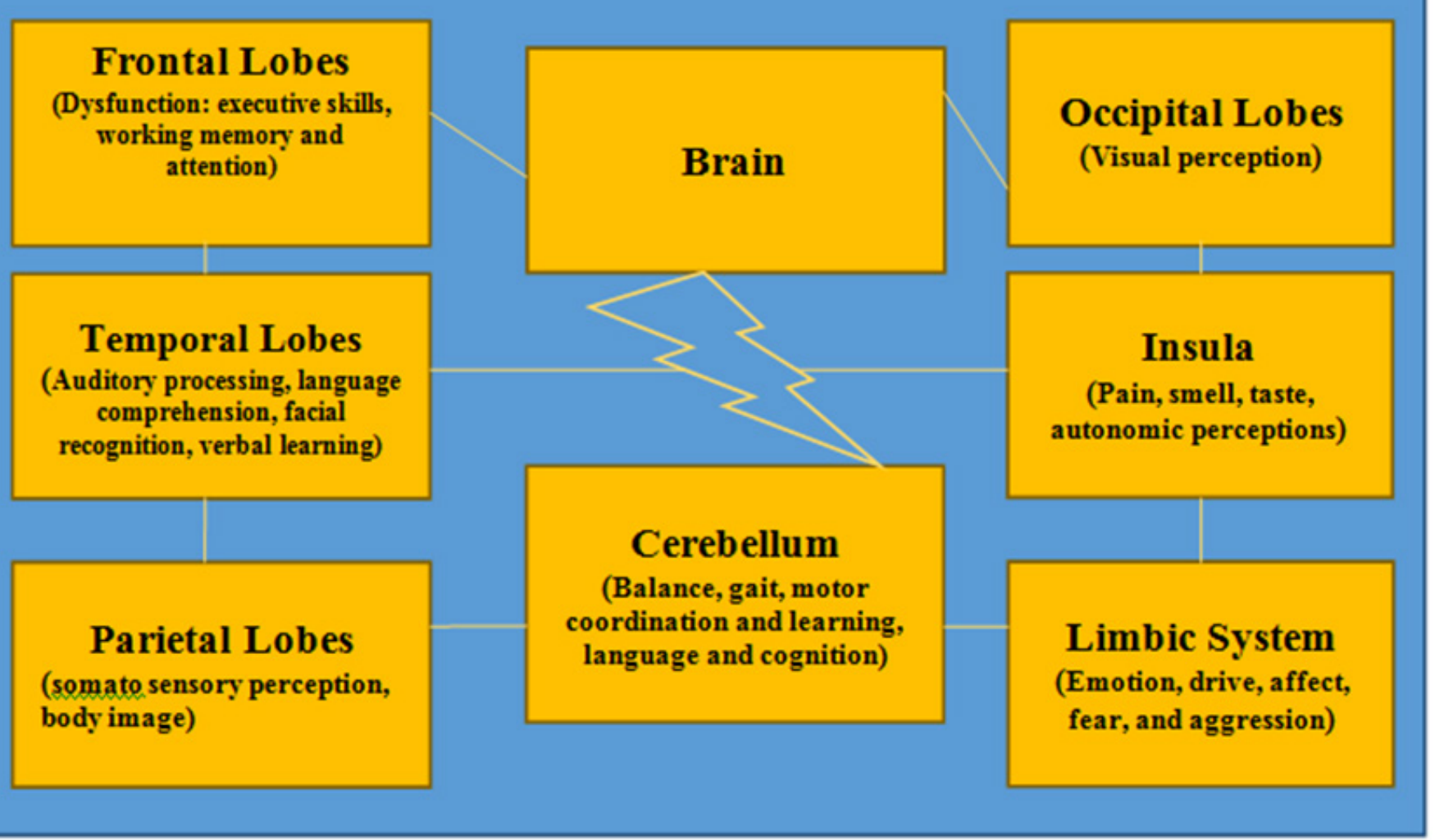

\section{Special Education Services by 2020}

The question is what will special education services look like by 2020 ? What are some of the challenges and issues for special education services specifically for our children with ASD? The population of the United States was estimated to be 250 million in 1990, and by the year of 2000 the diverse population had grown to more than 282 million [10]. The projections indicated that the population growth is going to exceed 349 million by the year 2025 and by 2050 will be nearly approximately
420 million. There has been twenty years of change in special education enrollment from 1995 to 2014. The U.S. Department of Education reported 2014-2015 that the number of students with specific disabilities increased to $165 \%$ for Autism by 2014 , $51 \%$ Other Health Impaired, 17\% Specific Learning Disabilities, $11 \%$ Speech and Language Impairments, 27\% Emotional and Behavior Disturbance, and 23\% Intellectual Disabilities nationwide. Challenges that continue for professionals are in some of the world's rural area schools and districts where 
less focus has been placed on special education classes, lack of funding, many professionals feel there is a lack of appreciation for the commitment that these professionals provide, parental support, paperwork, and most of all training.

However, what is not talked about is the reward for working with children with ASD to improve their lives which far outweighs the challenges and issues. For many years, professionals have had to educate others that special education is a system of service to meet and support the needs of children and their families with ASD. It is not a place. Some of the continued challenges that educational systems will face for special education services are the lack of highly qualified special education teachers, insufficient funding/budget cuts not only to education but also to related services and specific therapies for children diagnosed with ASD, teacher burnout, and retainment of teachers to fulfill the needs of the students [11]. The continued challenges are enormous. The Reauthorization of IDEA is long overdue, up to at least six years now. Educational systems are going to have to become creative, innovative, and technological savvy to address these challenges in meeting the needs of ASD children and provide the necessary tools and resources for children's academic success [12].

\section{References}

1. Vohra R, Madhavan S, Sambamoorthi U, St Peter C (2014) Access to services, quality of care, and family impact for children with autism, other developmental disabilities, and other mental health conditions. Autism 18(7): 815-826.

2. American Psychiatry Association (2016) What is Autism Spectrum Disorder?

3. Weiss JA, Baker JK, Butter EM (2016) Mental Health Treatment for People with Autism Spectrum Disorder (ASD). Spotlight on Disability Newsletter.

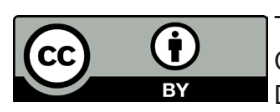

This work is licensed under Creative

Commons Attribution 4.0 Licens

DOI: 10.19080/GJIDD.2017.03.555625
4. Enwefa RL, Enwefa SC (2017) Educating Children with Autism and Sensory Processing Disorders in the Classroom. J Commun Disorder Assist Techno 1: 1-11.

5. Enwefa R, Enwefa S, Rey M, Green K, Jackson J (2014) Mealtime Challenges for Children with Autism Spectrum Disorders and Sensory Processing Disorders. Mississippi Speech-Language-Hearing Association Annual Continuing Education Conference Presentation Abstracts, Jackson, Mississippi, USA.

6. Christensen D, Bilder D, Zahorodny W, Pettygrove S, Durkin M, et al. (2016) Prevalence and Characteristics of Autism Spectrum Disorder among 4-year-old Children in the Autism and Developmental Disabilities Monitoring Network. Journal of Developmental and Behavioral Pediatrics, 37(1): 1-8.

7. Christensen DL, Baio J, Van Naarden Braun K, Bilder D, Charles J, et al. (2016) Prevalence and characteristics of autism spectrum disorder among children aged 8 years-Autism and Developmental Disabilities Monitoring Network, 11 sites, United States, 2012. MMWR Surveill Summ 65(3): 1-23.

8. National Institute of Mental Health (2016) Treatment of Children with Mental Illness. Frequently asked questions about the treatment of mental illness in children. Department of Health and Human Services, National Institutes of Health, USA.

9. Enwefa R, Enwefa S, Nyarambi A (2012) Speech-Language, Nutrition and Behavior Therapy for Autism Spectrum Disorders". Mississippi Speech Language Hearing Association Annual Continuing Education Conference Presentation Abstracts, Jackson, Mississippi, USA.

10. (2012) US Population Projections. US Census Bureau.

11. Enwefa RL, Enwefa SC, Jurden M, Banks IW, Buckley D (2002) Teaching Recruitment, Preparation and Retention in Mississippi: Issues and Solutions. The Alliance Project, Peabody College, Vanderbilt University, Nashville, Tennessee, USA.

12. Enwefa R, Enwefa S, Nyarambi A (2012b) Autism and Sensory Processing Disorders for Special Education Professionals, Speech Language Pathologists, and Other Health Professionals. National Association of African American Studies Education Monograph Series, Biddeford, Maine, USA.

\section{Your next submission with Juniper Publishers will reach you the below assets}

- Quality Editorial service

- Swift Peer Review

- Reprints availability

- E-prints Service

- Manuscript Podcast for convenient understanding

- Global attainment for your research

- Manuscript accessibility in different formats

( Pdf, E-pub, Full Text, Audio)

- Unceasing customer service

Track the below URL for one-step submission https://juniperpublishers.com/online-submission.php 